\title{
Regional variation in coronary heart disease mortality trends in Portugal, 1981-2012
}

\author{
Carla Araújo a,b,c,*,1 , Marta Pereiraa ${ }^{\mathrm{a}, 1}$, Marta Viana ${ }^{\mathrm{a}, 1}$, Olga Laszczyńska Rocha ${ }^{\mathrm{a}, 1}$, Kathleen Bennett ${ }^{\mathrm{d}, 1}$, \\ Nuno Lunet ${ }^{\mathrm{a}, \mathrm{b}, 1}$, Ana Azevedo ${ }^{\mathrm{a}, \mathrm{b}, 1}$

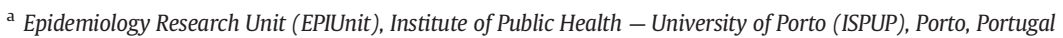 \\ ${ }^{\mathrm{b}}$ Department of Clinical Epidemiology, Predictive Medicine and Public Health, University of Porto Medical School, Porto, Portugal \\ c Department of Cardiology, Centro Hospitalar de Trás-os-Montes e Alto Douro, EPE, Hospital de São Pedro, Vila Real, Portugal \\ d Population Health Sciences Division, Royal College of Surgeons in Ireland, St Stephens Green, Dublin 2, Ireland
}

\section{A R T I C L E I N F O}

\section{Article history:}

Received 27 June 2016

Received in revised form 7 September 2016

Accepted 15 September 2016

Available online 16 September 2016

\section{Keywords:}

Coronary disease

Mortality

Trends

Portugal

\begin{abstract}
A B S T R A C T
Background: Information is scarce about the geographic variation in time trends of mortality from coronary heart disease (CHD). We aimed to describe trends in death rates, absolute number of deaths and years of life lost (YLL) due to CHD among men and women in Portugal, by region, from 1981 to 2012.

Methods: The age-standardized mortality rates from CHD were estimated by sex and region. We used joinpoint regression analysis to calculate the annual percent change (APC) in mortality and to identify points of significant change in the trend. The YLL due to premature mortality for CHD were computed using the Global Burden of Disease method.

Results: The age-adjusted mortality from CHD decreased between 1981 and 2012, both in men and women, but with significantly different APC by region. Smaller declines in rates were observed in Alentejo (men: APC 19932012: - 2.4\%; women: APC 1991-2012: -2.4\%). The greatest decline was observed in Madeira between 2003 and 2012, in men (APC: - 7.6\%) and women (APC: -9.7\%). The decline in rates in Algarve started only after 2003, whereas it was consistent from 1981 in the North and started in the 1990s in most other regions. A decrease in the number of deaths was only observed after 2000. The YLL from CHD decreased from 1981 to 2012, mainly after 2000.

Conclusions: In Portugal, between 1981 and 2012, relative declines of CHD mortality indicators were different by geographic region. Consistent decreases in mortality rates were only observed in the Centre, Lisbon and North, the most populated and urbanized regions.
\end{abstract}

(c) 2016 Elsevier Ireland Ltd. All rights reserved.

\section{Introduction}

Cardiovascular diseases (CVD) are the most common cause of death. In 2012, almost half of non-communicable disease deaths worldwide were caused by CVD (17.5 million deaths), more than double the number of deaths caused by cancers [1,2]. CVD are responsible for close to half of all deaths in Europe (over 4 million deaths per year), with coronary heart disease (CHD) accounting for $20 \%$ of all deaths in Europe annually (nearly 1.8 million deaths) [2]. The most up-to-date data on CVD still show disparities in the death rates between European countries, with Central and Eastern Europe having higher rates than Northern,

\footnotetext{
* Corresponding author at: Departamento de Epidemiologia Clínica, Medicina Preditiva e Saúde Pública, Faculdade de Medicina da Universidade do Porto, Alameda Prof. Hernâni Monteiro, 4200-319 Porto, Portugal.

E-mail address: carla-r-araujo@hotmail.com (C. Araújo).

1 This author takes responsibility for all aspects of the reliability and freedom from bias of the data presented and their discussed interpretation.
}

Southern and Western Europe [2]. Within-country CVD mortality inequalities have been reported in several European countries, by region, socioeconomic characteristics and country of birth [3-5].

CVD and CHD death rates have been consistently falling across most but not all European countries; the timing and magnitude of this decrease also vary [2]. CHD mortality trends may also be different by demographic groups, with young adults, especially women, experiencing smaller decreases in CHD mortality rates in the two last decades [6]. Specific indicators such as years of life lost are needed to capture premature mortality due to CHD.

In Portugal, the age-adjusted mortality from CVD, in 2011, was $174.7 / 100,000$ among men and 126.8/100,000 among women, and the age-adjusted mortality rates from CHD are among the lowest in Europe [2]. There was a decrease in the age-adjusted mortality from CVD between 1980 and 2010 [7], and also from CHD [2], but there is no information about the magnitude of these trends by region. Differences in health status by geographic region, namely in less populated and less urban regions, are among the sizeable inequalities identified 
in the Portugal health system performance assessment in 2010, conducted by the World Health Organization [8]. This report states that it is difficult to assess and monitor the extent of the health inequalities in Portugal, due to the lack of a monitoring system of health indicators by target population groups, owing, at least in part, to a narrow interpretation of the data confidentiality law. A recent ecological study showed geographic variation in hospital admissions and in-hospital mortality of patients admitted with ischemic heart disease in Portugal from 2000 to 2007, with the interior regions showing higher rates, not fully explained by socio-demographic, economical and health resource factors [9]. It is of interest to expand this observation to a longer period and to consider total mortality, in addition to in-hospital mortality.

We aimed to describe time trends in death rates, absolute number of deaths and YLL from CHD among men and women in Portugal, by region, during the period 1981-2012.

\section{Methods}

\subsection{Sources of data}

Estimates of population at risk as well as the number of deaths from CHD [International Classification of Diseases 9th revision clinical modification, (ICD 9 CM) 410-414] were obtained from official statistics $[10,11]$.

All data were obtained from 1981 to 2012 for each sex in age groups $(<1,1-4,5$-year age groups to $80-84$ and $\geq 85$ years), by region [Nomenclature of Territorial Units for Statistics (NUTS II): Alentejo, Algarve, Azores, Centre, Lisbon, Madeira and North].

\subsection{Trends in mortality rates}

We calculated age-standardized mortality rates per 100,000 by the direct method, using the European standard population (2013 revision) as reference [12].

To calculate the annual variation in mortality and to identify points of significant change in the log-linear slope of the trend (joinpoints) [13] we performed a joinpoint regression analysis, using Joinpoint ${ }^{\circledR}$ version 3.4 from the Surveillance Research Program of the US National Cancer Institute. The analysis starts with the minimum number of joinpoints, with no joinpoints corresponding to a straight line, testing if one or more joinpoints significantly improve model fit. We set the minimum number of years before the first, after the last and between consecutive joinpoints as five. The best fitting models for the trends are presented for men and women by region. The estimated annual percent change (APC) in mortality for each period was calculated taking the calendar year as the independent variable and assuming a Poisson distribution.

\subsection{Years of life los}

The years of life lost (YLL) due to premature mortality for CHD, by sex and age group, in each geographic region, were computed using the Global Burden of Disease method [14], by multiplying the number of deaths at each age by the life expectancy at the age at which death occurs. We considered the recommended standard life expectancy at birth of 80 years for men and 82.5 years for women. The average age at death was set to the mid-point of each five-year age group, except for the oldest group in whom it was assumed to be 87.5 years [14]. We applied a $3 \%$ time discount rate to assign less weight to the YLL corresponding to the periods more distant from the time of death than to those referring to the first years after death, an age-weighting parameter to weight YLL in the very young and the older ages less than other ages (Global Burden of Disease standard value is 0.04 ) and an age weighting correction constant so that the introduction of ageweights did not alter the total number of YLL (Global Burden of Disease standard value is 0.1658) [14]. The total YLL for each gender and region was obtained by summing the YLL of all age groups. Moving averages (over 3 years) for YLL were calculated.

\section{Results}

\subsection{Trends in mortality rates}

In Portugal, the age-adjusted mortality rates from CHD decreased between 1981 and 2012, both in men and women, though with different patterns by geographic region, both in magnitude and year of decline onset.

In Portugal, among men, age-standardized mortality rates decreased from $195.6 / 100,000$ in 1981 to $86.7 / 100,000$ in 2012; and among women, from 108.0/100, 000 to $50.0 / 100,000$, in the same period.

Among men, Azores and Alentejo were the two regions with the highest standardized mortality rates in 1981 (326.5/100,000 and $250.3 / 100,000)$, respectively and also in 2012 (174.9/100,000 and
$157.6 / 100,000$, respectively). In the remaining regions, the standardized mortality rates were similar among regions in 1981, ranging from 171.1/100,000 in Algarve to 186.4 in Lisbon, while in 2012 the North showed a lower standardized mortality rate than all other regions (66.4/100,000). Among women, Azores and Alentejo were also the two regions with the highest standardized mortality rates both in 1981 (148.4/100,000 and 164.6/100,000, respectively) and in 2012 (97.4/100,000 for both regions). In the remaining regions, the mortality rates in 1981 ranged from 87.1/100,000 in the Algarve to $139.7 / 100,000$ in Madeira, while the North ranked again as the region with the lowest mortality rate in 2012 (32.6/100,000) (Fig. 1).

When analysing the decreases in standardized mortality rates over the study period, in the whole country 1993 and 2003 mark inflexion points for progressively steeper declines in rates among men, with APC ranging from $-0.7 \%$ in $1981-1993$ to $-5.1 \%$ in $2003-2012$. Among women, inflexion points were observed in 1992 and 2003, with APC ranging from $-0.2 \%$ in $1981-1992$ to $-5.5 \%$ in $2003-2012$ (Table 1).

Among men, the decline in rates in Algarve and Madeira started later, only after 2003, whereas it was consistent from 1981 in the North and started in the nineties in the other regions. Among women, Algarve also started to experience a decrease in rates only after 2004, whereas the North and Centre had consistent decreases in rates from 1981, and from the nineties in the remaining regions, except for Madeira where a fluctuating pattern was observed (Table 1, Fig. 1).

Among men, smaller relative declines in CHD mortality rates were observed in Alentejo and in the Centre region (APC 1993-2012: $-2.4 \%$ and $-3.3 \%$, respectively), while among women the region with the smallest decline was Alentejo (APC 1991-2012: - 2.4\%) (Table 1, Fig. 1). The greatest relative decline was observed in Madeira for the period 2003 to 2012, both in men (APC: - 7.6\%) and in women (APC: $-9.7 \%$ ) (Table 1, Fig. 1).

The declines in mortality rates had similar magnitude over time between men and women, when analysing the country as a whole. However, in most regions, greater declines were observed among women compared to men, with larger sex differences in the Centre (APC: $-5.7 \%$ vs $-3.3 \%$; women vs men), followed by Madeira (APC: $-9.7 \%$ vs $-7.6 \%$ ) and the North (APC: $-6.2 \%$ vs $-4.3 \%$ ) (Table 1 ).

\subsection{Number of deaths and YLL}

Although the decrease in the age-adjusted mortality rates from CHD started in the nineties in the majority of the Portuguese regions, the decrease in the number of deaths was only observed after 2000 (Fig. 2).

All over the country, the YLL from CHD were significantly higher in men. The YLL from CHD decreased from 1981 to 2012, both among men and women, ranging from a $23.9 \%$ decrease in Alentejo to a $64.5 \%$ decrease in Madeira, among men, and from a 4.8\% decrease in Alentejo to a $57.8 \%$ decrease in Madeira, among women (Table 2). This decrease was mainly observed after the year 2000, and Lisbon and the North were the two geographic regions with lowest YLL, both in men and women, during the majority of the period studied (YLL in 2012, among men: 7.09/1000 population in Lisbon and 4.43/1000 population in the North; and among women: 4.91/1000 population in Lisbon and 2.70/1000 population in the North) (Table 2, Fig. 2).

\section{Discussion}

CHD mortality rates decreased in Portugal over the last 30 years, but with geographic disparities, meaning that cardiovascular health inequalities persisted in the country throughout this period. Azores and Alentejo started with the highest rates in 1981, and despite the decrease, still showed higher rates in 2012, although the difference from the other regions was attenuated. The North, on the other hand, had a mortality rate that was dissimilar to other regions, which began to diverge early in the nineties but maintaining the lowest rates until 2012. 

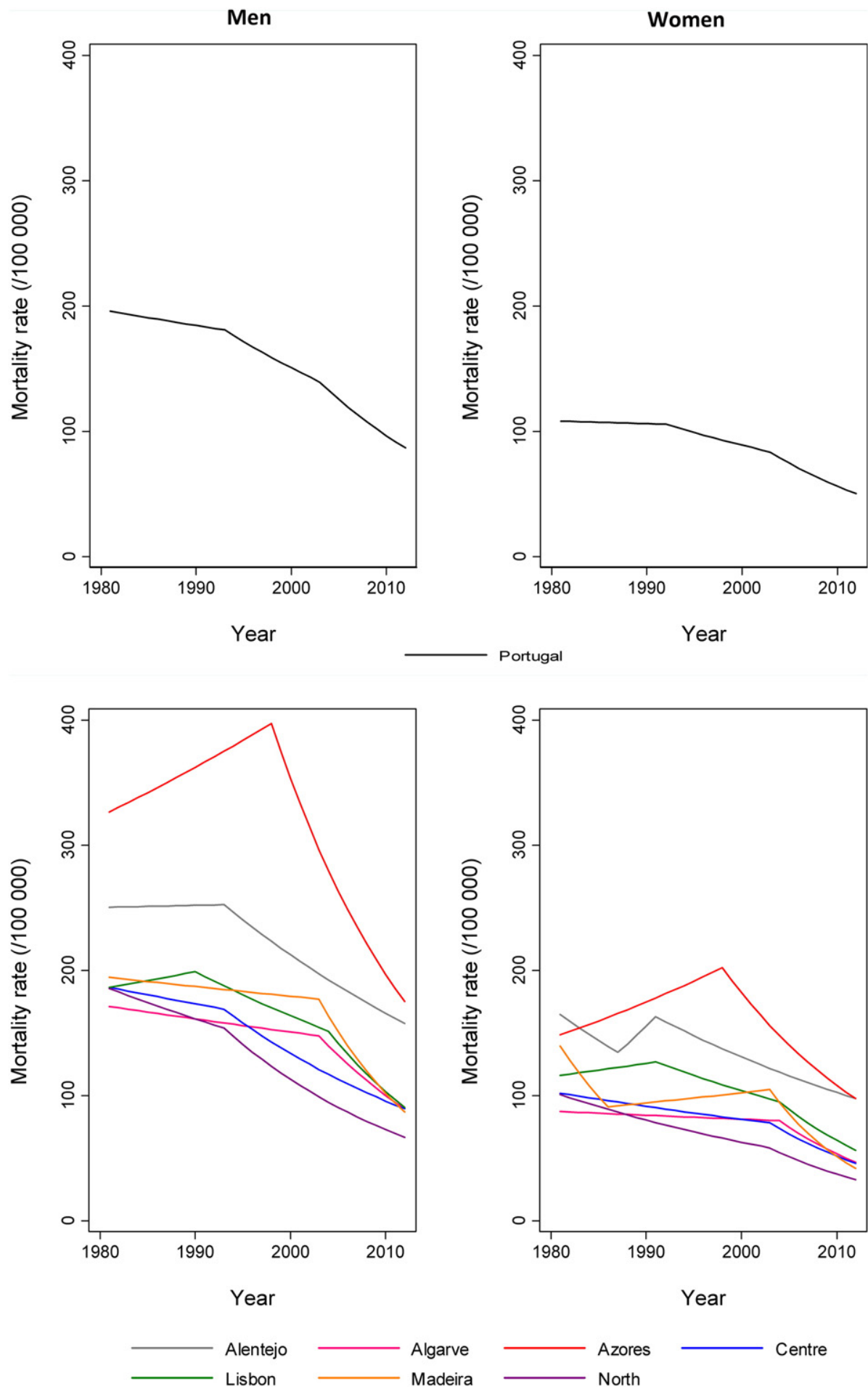

Fig. 1. Time trends in age standardized (European population) mortality rates for coronary heart disease, by sex and region, 1981-2012.

The YLL from CHD also decreased from 1981 to 2012 and the decrease in the number of deaths was only observed after 2000. The CHD mortality trends in Portugal are similar to those observed in other developed countries of the world, namely in Western Europe [15]. This decline has generally been described at the national level, which masks any existing differences between socioeconomic groups or geographic regions.

From 1981 to around 2000 the increase in the population size and the older age structure [11] exceeded the contribution of decrease in rates to a lower mortality burden, explaining an increase in the number of deaths due to CHD until 2000. The higher YLL from CHD in men is in accordance with the fact that the difference of CHD risk by sex is significantly larger in young people. Lisbon and the North are the two regions with the youngest population, explaining the lowest YLL observed [16].

The inequalities in CHD mortality trends by Portuguese region are dependent on two main domains, namely 1 ) the prevalence of cardiovascular risk factors and 2 ) health-care related factors, including the distribution and quality of health resources, access to the services and patterns of use of health care [17]. These factors are related not only with socioeconomic conditions, but also with lifestyle choices, 
Table 1

Annual percent change (95\% confidence intervals, CI) in coronary heart disease mortality rates, by sex and region, 1981-2012.

\begin{tabular}{|c|c|c|c|c|c|}
\hline \multicolumn{3}{|l|}{ Men } & \multicolumn{3}{|l|}{ Women } \\
\hline Period $^{a}$ & Mortality rate $^{\mathrm{b}}$ & $\mathrm{APC}, \%(95 \% \mathrm{CI})^{\mathrm{C}}$ & Period $^{\mathrm{a}}$ & Mortality rate $^{\mathrm{b}}$ & APC, $\%(95 \% \mathrm{CI})^{\mathrm{c}}$ \\
\hline \multicolumn{6}{|l|}{ Portugal } \\
\hline $1981-1993$ & 195.6 & $-0.7(-1.2$ to -0.1$)$ & 1981-1992 & 108.0 & $-0.2(-1.0$ to 0.6$)$ \\
\hline $1993-2003$ & 180.7 & $-2.6(-3.4$ to -1.8$)$ & $1992-2003$ & 105.6 & $-2.1(-2.9$ to -1.4$)$ \\
\hline 2003-2012 & 139.2 & $-5.1(-5.9$ to -4.3$)$ & 2003-2012 & 83.3 & $-5.5(-6.4$ to -4.6$)$ \\
\hline \multicolumn{6}{|l|}{ Alentejo } \\
\hline 1981-1993 & 250.3 & $0.1(-1.0$ to 1.2$)$ & 1981-1987 & 164.6 & $-3.3(-6.7$ to 0.2$)$ \\
\hline \multirow{2}{*}{$1993-2012$} & 252.4 & $-2.4(-3.0$ to -1.9$)$ & 1987-1991 & 134.4 & $4.9(-4.5$ to 15.3$)$ \\
\hline & & & 1991-2012 & 163.0 & $-2.4(-2.9$ to -2.0$)$ \\
\hline \multicolumn{6}{|l|}{ Algarve } \\
\hline $1981-2003$ & 171.1 & $-0.7(-1.4$ to 0.0$)$ & 1981-2004 & 87.1 & $-0.4(-1.2$ to 0.4$)$ \\
\hline 2003-2012 & 148.0 & $-5.4(-7.8$ to -2.9$)$ & 2004-2012 & 79.8 & $-6.5(-10$ to -2.8$)$ \\
\hline \multicolumn{6}{|l|}{ Azores } \\
\hline 1981-1998 & 326.5 & $1.2(0.4$ to 1.9$)$ & 1981-1998 & 148.3 & $1.8(0.7$ to 3.0$)$ \\
\hline $1998-2012$ & 397.1 & $-5.7(-6.7$ to -4.7$)$ & 1998-2012 & 202.0 & $-5.1(-6.5$ to -3.7$)$ \\
\hline \multicolumn{6}{|l|}{ Centre } \\
\hline $1981-1993$ & 186.3 & $-0.8(-1.8$ to 0.2$)$ & 1981-2003 & 101.8 & $-1.2(-1.6$ to -0.8$)$ \\
\hline $1993-2012$ & 168.9 & $-3.3(-3.8$ to -2.8$)$ & 2003-2012 & 78.0 & $-5.7(-7.7$ to -3.8$)$ \\
\hline \multicolumn{6}{|l|}{ Lisbon } \\
\hline $1981-1990$ & 186.4 & $0.7(-0.7$ to 2.2$)$ & 1981-1991 & 116.0 & $0.9(-0.2$ to 2.0$)$ \\
\hline 1990-2004 & 198.8 & $-1.9(-2.6$ to -1.3$)$ & 1991-2004 & 126.7 & $-2.2(-2.9$ to -1.5$)$ \\
\hline 2004-2012 & 151.3 & $-6.2(-7.5$ to -4.9$)$ & 2004-2012 & 94.9 & $-6.3(-7.7$ to -5.0$)$ \\
\hline \multicolumn{6}{|l|}{ Madeira } \\
\hline $1981-2003$ & 194.3 & $-0.4(-1.4$ to 0.6$)$ & 1981-1986 & 139.7 & $-8.2(-15.2$ to -0.7$)$ \\
\hline \multirow[t]{2}{*}{ 2003-2012 } & 177.0 & $-7.6(-11.6$ to -3.4$)$ & 1986-2003 & 90.9 & $0.8(-0.5$ to 2.1$)$ \\
\hline & & & 2003-2012 & 104.6 & $-9.7(-12.8$ to -6.5$)$ \\
\hline \multicolumn{6}{|l|}{ North } \\
\hline 1981-1993 & 185.5 & $-1.5(-2.5$ to -0.5$)$ & 1981-2003 & 100.7 & $-2.5(-3.2$ to -1.7$)$ \\
\hline 1993-2012 & 153.8 & $-4.3(-4.8$ to -3.8$)$ & 2003-2012 & 58.1 & $-6.2(-9.0$ to -3.3$)$ \\
\hline
\end{tabular}

a Periods with constant log-linear trend identified in the joinpoint analysis.

b Mortality rate $(/ 100,000)$, estimated age-standardized mortality rate at the beginning of the respective period.

c APC, annual percent change; $95 \% \mathrm{CI}, 95 \%$ confidence interval.

structured by cultural forces, often operating in opposite directions. For instance, in Portugal, those forces promote the Mediterranean diet and at the same time smoking among women [17].

The contribution of the reduction in risk factors to the decline of Portuguese CHD mortality from 1995 to 2008 was estimated to be $42 \%$ and the increase in the uptake of treatments contributed approximately $50 \%$ [17]. Previous studies have analysed trends in the prevalence or means of cardiovascular risk factors in Portugal [18-20]. In the last decades there was a decrease in blood pressure levels, observed in middleaged and older adults, while among young adults the levels remained approximately constant [18]. Self-reported diabetes and overweight/ obesity, on the other hand, increased in both sexes; while smoking prevalence increased only among women [17,19-21]. These estimates, very important to understand the main determinants of the CHD mortality decline in Portugal, certainly conceal different proportions across geographic regions.

There is no systematic and comprehensive information available about trends in risk factors by Portuguese regions, but cross-sectional studies on some cardiovascular risk factors distribution by Portuguese region convey relevant information. According to the AMALIA study [22], which included 38,893 individuals, with regional, gender and age-group distribution representative of the Portuguese population, between October 2006 and February 2007, Azores, one of the regions with the highest standardized mortality rate over the last three decades, was the region with the highest prevalence of self-reported hypertension (35.6\%), hypercholesterolemia (25.6\%), diabetes (15.4\%) and overweight/obesity (77.7\%). Algarve, Madeira and the North were the regions with the lowest prevalence of hypercholesterolemia (15.6, 15.8 and $15.9 \%$, respectively); Algarve and the North had also the lowest prevalence of hypertension (18.3 and 19.3\%, respectively) and diabetes
(9.1 and 6.5\%, respectively). The North had the lowest prevalence of overweight/obesity (41.3\%). Algarve was the region with the highest self-reported prevalence of smoking (20.3\%), and Madeira and the Centre region the lowest (11.9 and $12.8 \%$, respectively). According to the VALSIM study [23], carried out between April 2006 and November 2007, there were significant regional variations in the prevalence of metabolic syndrome, adjusted for gender and age: residents in the Algarve or in Lisbon and Tagus Valley had lower prevalence [odds ratio (OR) (95\% confidence interval): 0.78 (0.66-0.92) and 0.83 (0.770.91 ), respectively], while residents in the North or Centre regions had higher prevalence (OR (95\% confidence interval): 1.11 (1.01-1.21) and 1.08 (1.002-1.16), respectively). After adjusting for gender and age, the higher prevalence in Alentejo residents was no longer observed, probably due to its elderly population. Considering a possible different individual's global risk of developing CHD profile by region and therefore a probable different need of risk-factor lowering treatment for CHD primary prevention within Portugal, data on time trends of different drugs utilization by region, namely statins and blood pressure lowering agents, would help to compare CHD risk level and risk-factor lowering treatment, analysing the importance of evidence based treatment in the reduction of $\mathrm{CHD}$ mortality by region. If regions with a faster reduction in CHD mortality showed a larger increase in risk-factor lowering treatment, a positive effect of these agents on CHD mortality and a risk-based prescription would be supported; however if a "discordant" relation (slower reduction in mortality accompanied by a larger increase in prescription) was observed, which was already observed with statins in other settings [24], other factors apart from the actual risk of the patients would emerge as an explanation. Available data do not allow the quantification of time trends in cardiovascular risk factors by region, which would help to better understand the determinants of 
Men
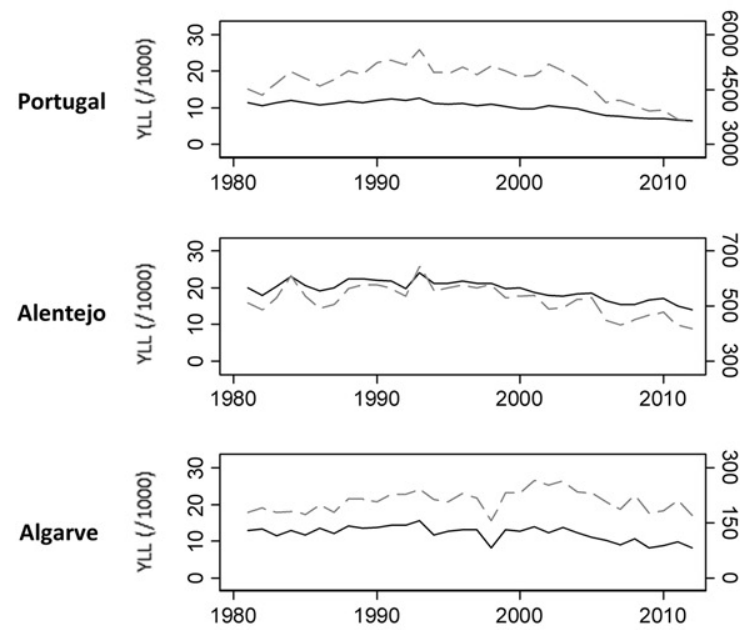

Azores

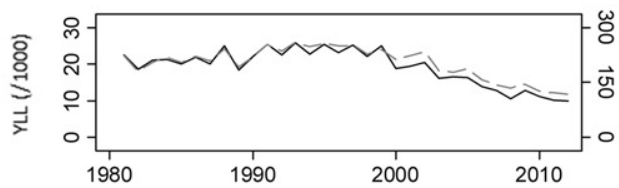

Centre

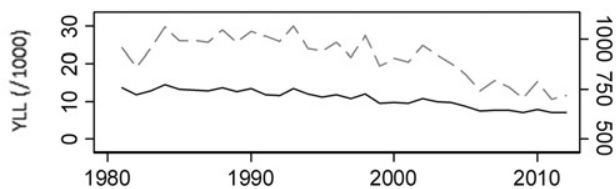

Lisbon
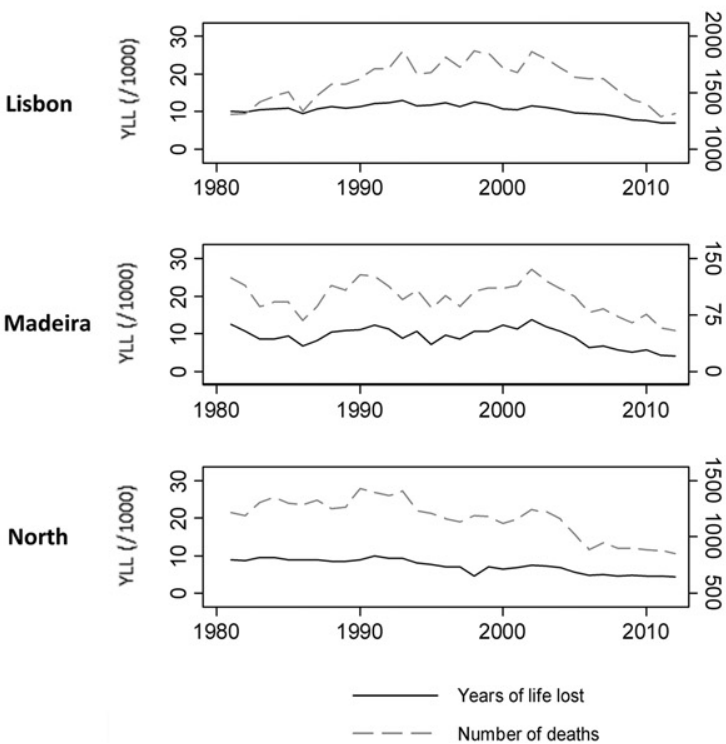

Women
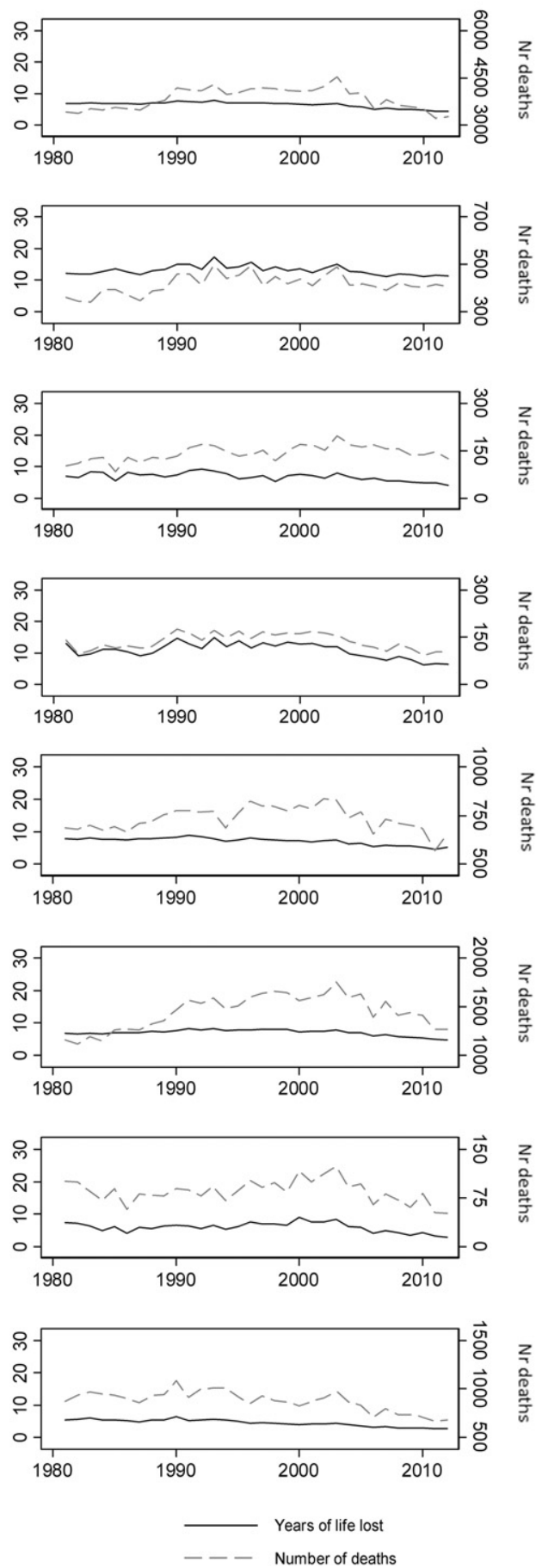

Fig. 2. Time trends in years of life lost and in number of deaths for coronary heart disease, by sex and region, 1981-2012.

the different patterns of coronary disease mortality declines observed, we expect that these differences are partly explained by an unequal prevention and control of risk factors per region.

The National Health Service (NHS) provides universal coverage, financed mainly through taxation, which should ensure avoidance of inequalities, at least in access to care. Treatment of CHD in Portugal should therefore be equitable and based on clinical need, and not dependent on age, sex, race, region of residence and other socio-economic factors. Indeed the majority of acute coronary events are treated in public hospitals, but long-term care of patients is also carried out by other providers, both public and private [25]. Besides the NHS, the Portuguese health care system has two other coexisting and overlapping players: special public and private insurance schemes for certain professions (health subsystems) and private voluntary health insurance. Public provision is particularly responsible for primary and hospital care. Specialist consultations and diagnostic services, among other treatments, are commonly provided also in the private sector, less accessible to the general population [26]. Despite the NHS' supposed universal coverage, the geographic distribution of health resources is heterogeneous [25]. Algarve and Alentejo are the regions with the lowest number of hospital beds ( 2.1 and 2.2 per 1000 inhabitants in 2010, respectively). Azores and Alentejo are the regions with the lowest physician workforce, approximately 2 doctors per 1000 inhabitants, about half the number at the national level [27]. Additionally there are several access indicators, 
Table 2

Years of life lost from 1981 to 2012, by region and sex.

\begin{tabular}{|c|c|c|c|c|c|c|}
\hline & \multicolumn{3}{|l|}{ Men } & \multicolumn{3}{|c|}{ Women } \\
\hline & \multicolumn{2}{|l|}{$\mathrm{YLL}^{\mathrm{a}}$} & \multirow{2}{*}{$\frac{\text { YLL }^{\mathrm{a}} \text { reduction }(\%)}{1981-2012}$} & \multicolumn{2}{|l|}{$\mathrm{YLL}^{\mathrm{a}}$} & \multirow{2}{*}{$\frac{\text { YLL }^{\mathrm{a}} \text { reduction }(\%)}{1981-2012}$} \\
\hline & 1981 & 2012 & & 1981 & 2012 & \\
\hline Portugal & 11.05 & 6.60 & 40.3 & 6.9 & 4.4 & 36.2 \\
\hline Alentejo & 18.99 & 14.46 & 23.9 & 12.06 & 11.48 & 4.8 \\
\hline Algarve & 13.10 & 9.05 & 30.9 & 6.74 & 4.44 & 34.1 \\
\hline Azores & 20.60 & 10.11 & 50.9 & 11.07 & 6.53 & 41.0 \\
\hline Centre & 12.75 & 7.15 & 43.9 & 7.75 & 4.87 & 37.2 \\
\hline Lisbon & 10.09 & 7.09 & 29.7 & 6.65 & 4.91 & 26.2 \\
\hline Madeira & 11.58 & 4.11 & 64.5 & 7.25 & 3.06 & 57.8 \\
\hline North & 8.82 & 4.43 & 49.8 & 5.52 & 2.70 & 51.1 \\
\hline
\end{tabular}

a YLL, years of life lost in years. The YLL of each year was calculated as the moving average over 3 years.

directly related to CHD outcomes, with clear differences by region. Some of these indicators have improved in the last years at the national level, namely the number of patients submitted to primary percutaneous coronary intervention (primary PCI), that increased by $37.0 \%$ from 2009 to 2013 , the mean delay time to coronary angiography, that decreased from 22.3 days in 2009 to 13.7 days in 2013, or the number of patients admitted through the coronary fast-track system that increased by $80.5 \%$ from 2009 to 2013 . However, at the region level, these improvements were not of the same magnitude. Considering specific cardiac procedures, in 2013, Alentejo was the region with the lowest number of patients submitted to primary PCI (170.9 per million of inhabitants) and with the highest mean delay time after a coronary angiography is indicated (30 days). Lisbon and the Algarve were the regions with the highest number of patients submitted to primary PCI (506.4 and 429.5 per million of inhabitants, respectively); and Algarve and the North were the regions with the lowest mean delay time after a coronary angiography is indicated ( 2 and 8.2 days, respectively). Additionally the coronary fast-track system was not implemented at the same time in the different Portuguese regions, with Alentejo being the region with the latest implementation [25]. Despite the increase in the use of recommended pharmacological therapy for secondary prevention after an ACS during hospitalization and at hospital discharge over the last two decades in Portugal [28], there is no information on trends of utilization of these drugs in this group of patients by region. Treatment with invasive procedures may be dependent on access determinants, namely access to catheterization laboratories, but the prescription of pharmacological treatment during hospitalization and at discharge only depends on the medical decision. It would be important to evaluate variation in trends of utilization of pharmacological therapy for secondary prevention of ACS by region, and to understand their role in the different patterns of decrease in mortality observed. All these data suggest that the factors that determine the observed trends, even in regions with similar CHD mortality trends, play through different causality pathways. Understanding the specific pathways operating in each region has the potential to further reduce the burden of CHD.

Considering the five main patterns of CHD mortality trends at country level recently proposed, Portugal was included in a pattern characterized by the lowest age-standardized mortality rate and with a consistent decrease throughout the period of analysis [29]. The Centre, Lisbon and the North regions, where most of the population lives, a young and more educated population that lives predominantly in urban areas [16], were closest to this same pattern, while the remaining regions were more similar to a pattern characterized by higher rates observed until later, after 2000. This difference shows inequalities in cardiovascular health by region.

When analysing the CHD mortality trends by sex, we found greater declines among women. The most consistent sex differences in adult global mortality are attributed to CHD, which is the most common vascular condition with consistently greater age-adjusted mortality rates and risks in men than women, across different countries [2]. Lower
CHD mortality rates among women are explained by a better risk factor profile, even though there is evidence of higher in-hospital mortality after a cardiovascular event and lower access to evidence-based secondary prevention [30]. The smaller sex difference in CVD mortality after midlife has traditionally been related to postmenopausal oestrogen deficiency in women [31], but it might also be explained by the deceleration of the age-related increase in male specific mortality in midlife, whereas women's mortality rates steadily increase with age, with no significant or particular change at menopause [32]. The fact that greater declines were observed among women might be the result of effective primary and/or secondary prevention measures implemented among this group. Despite the slight increase in the prevalence of smoking among women, changes in the major cardiovascular risk factors in Portugal contributed significantly more to the CHD decrease among women than among men ( $58 \%$ vs $29 \%$ ), with greater differences by sex observed in the decrease in the mean population systolic blood pressure ( $6.5 \mathrm{~mm} \mathrm{Hg}$ in men and $12.4 \mathrm{~mm} \mathrm{Hg}$ in women), that were estimated to have prevented or postponed $40 \%$ of deaths in men and $72 \%$ in women [17]. Interestingly, the effect of antihypertensive treatment was small, similar in men and women, and therefore this difference was mainly attributable to lifestyle changes [17]. The greater declines in CHD mortality among women are also in accordance with a recent study showing improvements in sex-differences in discharge medications of patients admitted with acute coronary syndromes in Portugal, after adjusting for the potential confounding effect of age, co-morbidities, and contraindications [33].

\section{Limitations}

The key factor to correctly interpret these results is good-quality data on mortality, dependent on the coverage, accuracy of diagnosing causes of death and correct coding. Portuguese mortality data have high coverage and the underlying cause of death is certified by a medical practitioner. Nevertheless there is still a high proportion of deaths (17\%) coded as ill-defined causes [34] and validation studies are needed to better measure the accuracy of causes of death diagnosis.

Although we used ICD-9, which has considerably less detail than ICD-10, we are measuring CHD as a large group, without needing specific codes, which minimizes errors, even considering changes in coding rules and revisions done during the period of the study.

\section{Conclusion}

Despite the large decrease in age-adjusted mortality and in the YLL from CHD observed in Portugal, between 1981 and 2012, relative declines and the respective periods were different by geographic region. Recognition of these inequalities clearly underlies the need to implement an objective and systematic approach to monitor cardiovascular risk factor prevalence and proportion of control, and uptake of evidence-based treatments, both during acute events and in more stable phases, by region. Good quality data on determinants of CHD incidence and mortality by region are essential to define specific targets for intervention.

\section{Conflict of interest}

The authors declare that they have no conflict of interest. For this type of study formal consent is not required.

\section{Funding}

This project was supported by FEDER funds from Programa Operacional Factores de Competitividade - COMPETE (FCOMP-010124-FEDER-028709) and by national funds from the Portuguese Foundation for Science and Technology, Lisbon, Portugal (PTDC/DTP-EPI/ 0434/2012). Epidemiology Research Unit (EPIUnit) is funded by the 
Portuguese Foundation for Science and Technology (UID/DTP/04750/ 2013).

\section{References}

[1] S. Mendis, Global Status Report on Noncommunicable Diseases 2014, World Health Organization, Report, 2014

[2] M. Nichols, N. Townsend, P. Scarborough, M. Rayner, Cardiovascular disease in Europe 2014: epidemiological update, Eur. Heart J. 35 (2014) 2929.

[3] V. Siegler, A. Langford, B. Johnson, Regional differences in male mortality inequalities using the National Statistics Socio-Economic Classification, England and Wales, 2001-03, Health Stat. Q. 6-17 (2008).

[4] A. Langford, B. Johnson, A. Al-Hamad, Social inequalities in female mortality by region and by selected causes of death, England and Wales, 2001-03, Health Stat. Q. 44 (2009) 7-26.

[5] S.B. Rafnsson, R.S. Bhopal, C. Agyemang, A. Fagot-Campagna, S. Harding, N. Hammar, et al., Sizable variations in circulatory disease mortality by region and country of birth in six European countries, Eur. J. Pub. Health 23 (2013) 594-605.

[6] K.A. Wilmot, M. O'Flaherty, S. Capewell, E.S. Ford, V. Vaccarino, Coronary heart disease mortality declines in the United States from 1979 through 2011: evidence for stagnation in young adults, especially women, Circulation 132 (11) (2015) 997-1002.

[7] M. Pereira, B. Peleteiro, S. Capewell, K. Bennett, A. Azevedo, N. Lunet, Changing patterns of cardiovascular diseases and cancer mortality in Portugal, 1980-2010, BMC Public Health 12 (2012) 1126.

[8] World Health Organization, Portugal health system performance assessment 2010, http://www.euro.who.int/en/countries/portugal/publications2/portugal-healthsystem-performance-assessment-2010/2010 accessed 16.02.03.

[9] L.M. Ferreira-Pinto, F. Rocha-Goncalves, A. Teixeira-Pinto, An ecological study on the geographic patterns of ischaemic heart disease in Portugal and its association with demography, economic factors and health resources distribution, BMJ Open 2 (2012).

[10] Statistics Portugal, Coronary disease deaths between 1980 and 2012 by region (NUTS-II) and sex, http://www.ine.pt/xportal/xmain?xpid=INE\&xpgid=ine main/2013 accessed 15.08.13.

[11] Statistics Portugal, Resident population, http://www.ine.pt/xportal/xmain?xpid= INE\&xpgid=ine_main/2013 accessed 15.08 .13 .

[12] Office for National Statistics, European standard population (2013 revision), http:// www.ons.gov.uk/ons/guide-method/user-guidance/health-and-life-events/revisedeuropean-standard-population-2013-2013-esp-/index.html/2013 accessed 14.07 .11 .

[13] H.J. Kim, M.P. Fay, E.J. Feuer, D.N. Midthune, Permutation tests for joinpoint regression with applications to cancer rates, Stat. Med. 19 (2000) 335-351.

[14] C. Mathers, T. Vos, A. Lopez, J. Salomon, M. Ezatti, National burden of disease studies: a practical guide, Global Program on Evidence for Health Policy, 20th edWorld Health Organization, Geneva, 2001.

[15] M. Nichols, N. Townsend, P. Scarborough, M. Rayner, Trends in age-specific coronary heart disease mortality in the European Union over three decades: 1980-2009, Eur. Heart J. 34 (2013) 3017-3027.

[16] PORDATA, Base de Dados Portugal Contemporâneo, http://www.pordata.pt/ Municipios/Ambiente+de+Consulta/Tabela/2015 accessed 15.09.16.
[17] M. Pereira, A. Azevedo, N. Lunet, H. Carreira, M. O'Flaherty, S. Capewell, et al., Explaining the decline in coronary heart disease mortality in Portugal between 1995 and 2008, Circ. Cardiovasc. Qual. Outcomes 6 (2013) 634-642.

[18] M. Pereira, H. Carreira, C. Vales, V. Rocha, A. Azevedo, N. Lunet, Trends in hypertension prevalence (1990-2005) and mean blood pressure (1975-2005) in Portugal: a systematic review, Blood Press. 21 (2012) 220-226.

[19] M. Pereira, H. Carreira, N. Lunet, A. Azevedo, Trends in prevalence of diabetes mellitus and mean fasting glucose in Portugal (1987-2009): a systematic review, Public Health 128 (2014) 214-221.

[20] H. Carreira, M. Pereira, A. Azevedo, N. Lunet, Trends of BMI and prevalence of overweight and obesity in Portugal (1995-2005): a systematic review, Public Health Nutr. 15 (2012) 972-981.

[21] H. Carreira, M. Pereira, A. Azevedo, N. Lunet, Trends in the prevalence of smoking in Portugal: a systematic review, BMC Public Health 12 (2012) 958.

[22] C. Perdigao, E. Rocha, J.S. Duarte, A. Santos, A. Macedo, Prevalence and distribution of the main cardiovascular risk factors in Portugal-the AMALIA study, Rev. Port. Cardiol. 30 (2011) 393-432.

[23] M. Fiuza, N. Cortez-Dias, S. Martins, A. Belo, Metabolic syndrome in Portugal: prevalence and implications for cardiovascular risk-results from the VALSIM Study, Rev. Port. Cardiol. 27 (2008) 1495-1529.

[24] F. Vancheri, Trends in coronary heart disease mortality and statin utilization in two European areas with different population risk levels: Stockholm and Sicily, Int. Cardiovasc. Forum J. 1 (2014) 140-146.

[25] R. Ferreira, R. Neves, V. Rodrigues, Portugal - Doenças Cérebro-Cardiovasculares em números - 2014, Report, Direção-Geral da Saúde, November 2014.

[26] M.R. Giraldes, Desigualdades regionais nos subsistemas de saúde em Portugal, Análise Soc. XXXVII (164) (2002) 939-947.

[27] Centro de Investigação e Estudos de Sociologia, Instituto Universitário de Lisboa. Observatory of inequalities, http://observatorio-das-desigualdades.cies.iscte.pt/index. jsp? page $=$ indicators\&type $=\&$ lang $=$ pt $\&$ category $=$ saude $/ 2015$ accessed 15.05 .06 .

[28] M. Pereira, L. Lopes-Conceicao, K. Bennett, P. Dias, O. Laszczynska, N. Lunet, et al., Trends in pharmacological therapy following an acute coronary syndrome in Portugal: a systematic review, J. Cardiovasc. Med. (Hagerstown) 17 (2016) 639-646.

[29] C. Gouvinhas, M. Severo, A. Azevedo, N. Lunet, Worldwide patterns of ischemic heart disease mortality from 1980 to 2010, Int. J. Cardiol. 170 (2014) 309-314.

[30] S.S. Anand, C.C. Xie, S. Mehta, M.G. Franzosi, C. Joyner, S. Chrolavicius, et al. Differences in the management and prognosis of women and men who suffer from acute coronary syndromes, J. Am. Coll. Cardiol. 46 (2005) 1845-1851.

[31] A.S. Go, D. Mozaffarian, V.L. Roger, E.J. Benjamin, J.D. Berry, W.B. Borden, et al., Heart disease and stroke statistics-2013 update: a report from the American Heart Association, Circulation 127 (2013) e6-e245.

[32] D. Vaidya, D.M. Becker, V. Bittner, R.A. Mathias, P. Ouyang, Ageing, menopause, and ischaemic heart disease mortality in England, Wales, and the United States: modelling study of national mortality data, BMJ 343 (2011) d5170.

[33] M. Pereira, C. Araujo, P. Dias, N. Lunet, I. Subirana, J. Marrugat, et al., Age and sex inequalities in the prescription of evidence-based pharmacological therapy following an acute coronary syndrome in Portugal: the EURHOBOP study, Eur. J. Prev. Cardiol. 21 (2014) 1401-1408

[34] World Health Organization, Global Health Observatory data repository, http://apps. who.int/gho/data/node.main.121?lang=en/2014 accessed 16.03.25. 